\title{
Direct conversion of syngas to aromatics: A review of recent studies
}

\author{
Xiaoli Yang a,b,c, Xiong Su a, De Chen c, Tao Zhang a,b, Yanqiang Huang a,* \\ a State Key Laboratory of Catalysis, Dalian Institute of Chemical Physics, Chinese Academy of Sciences, Dalian 116023, Liaoning, China \\ b University of Chinese Academy of Sciences, Beijing 100049, China \\ c Department of Chemical Engineering, Norwegian University of Science and Technology, 7494 Trondheim, Norway
}

\section{A R T I C L E I N F O}

\section{Article history:}

Received 17 September 2019

Accepted 27 October 2019

Published 5 April 2020

\section{Keywords:}

Syngas

Aromatics

Modified FT catalyst

Composite catalyst

Reactor

\begin{abstract}
A B S T R A C T
The direct catalytic conversion of syngas to aromatics offers a promising route to manufacture fine chemicals by employing non-petroleum carbon resources, because aromatic constituents are the key platform for producing polymers. However, this remains a great challenge due to the low yield of aromatics and poor catalyst stability, which restrict further development. In recent years, extensive research has been reported on the design of effective catalysts and the optimization of operating conditions to obtain better catalytic performance. In this review, we focus on these related achievements and present a comprehensive overview of different kinds of catalysts, mainly including modified Fischer-Tropsch (FT) catalysts and composite catalysts, as well as their performance and reaction mechanisms. The thermodynamic analysis of the reactions involved in this innovative conversion process and the comparison of different methods are also described in detail in this updated review. Finally, the challenges and prospects for direct syngas conversion are discussed to provide general guidelines for the construction of a well-designed reaction route.
\end{abstract}

(C) 2020, Dalian Institute of Chemical Physics, Chinese Academy of Sciences. Published by Elsevier B.V. All rights reserved.

\section{Introduction}

In recent decades, gradual industrial development and accelerating energy consumption have led to a rapidly dwindling supply of petroleum fuels [1,2]. Hence, the exploration of other sustainable energy resources is urgently required to alleviate this crisis [3,4]. Syngas (a mixture gas of $\mathrm{CO}$ and $\mathrm{H}_{2}$ ) derived from coal, biomass, natural gas or organic waste has attracted wide interest from both academic and industrial application perspectives as it is a large reserve of carbon and hydrogen $[5,6]$. Through the process of Fischer-Tropsch (FT) synthesis or other catalytic reactions, syngas can be effectively converted into various fuels and chemicals, such as methanol, light olefins, and liquid hydrocarbons [7-11]. Some of these technologies have also been industrialized; for example, a 4000000-ton per year coal-to-liquids device funded by the Shenhua Ningxia Coal Industry Group of China was successfully commissioned and operated steadily in 2016. However, the products of FT synthesis are mainly linear hydrocarbons following the Anderson-Schulz-Flory (ASF) distribution, and need further separation treatments to satisfy the market demand.

Aromatics are one of the most fundamental bulk commodities and feedstocks in industry, which are not only used in blending mixtures of gasoline with a high-octane number, but also widely applied in producing various chemicals, like plastics, pesticides, solvents and pigment dyes [12-14]. They occupy almost one-third of the commodity petrochemical market and the demand is growing steadily because of the rapid de-

\footnotetext{
* Corresponding author. Tel: +86-411-84685940; E-mail: yqhuang@dicp.ac.cn

The authors gratefully acknowledge the National Key R\&D Program of China (2016YFA0202804), the Strategic Priority Research Program of the Chinese Academy of Sciences (XDB17020400), the National Natural Science Foundation of China (21506204, 21476226), Dalian Science Foundation for Distinguished Young Scholars (2016RJ04), and the Youth Innovation Promotion Association CAS for financial support. DOI: S1872-2067(19)63346-2 | http://www.sciencedirect.com/science/journal/18722067 | Chin. J. Catal., Vol. 41, No. 4, April 2020
} 
velopment of the polymer industry. Benzene, toluene, xylene (BTX) and the value-added durene are especially in high demand $[15,16]$. Currently, the majority of aromatics are produced via catalytic reforming of naphtha and thermal catalytic cracking of hydrocarbons, both of which heavily depend on petroleum $[17,18]$. Several alternative and efficient routes beyond petroleum-based processes have been developed. The aromatization of methane or light hydrocarbons offers a promising method for the replenishment of aromatics [19,20]. Wang et al. [21] firstly investigated the dehydroaromatization of methane to benzene over Mo/ZSM-5 and Zn/ZSM-5 at $973 \mathrm{~K}$ in 1993. Subsequently, several other research groups adopted this method and improved the desired aromatic selectivity [22,23]. Comparatively, the conversion efficiency can be enhanced and the reaction temperature is much lower when using other kinds of light hydrocarbons as feedstock. However, the selectivity of aromatic hydrocarbons seldom exceeds $60 \%$ based on the carbon number when using low-carbon olefins and alkanes over metal-modified zeolite catalysts [24,25]. Another approach is the production of aromatics from methanol, which has been developed into a mature technology very recently $[17,26]$. Freeman et al. [27] reported that the aromatic yield from methanol was markedly high over a $\mathrm{Ga}_{2} \mathrm{O}_{3}$-modified HZSM-5 catalyst. The conversion of dimethyl ether and other high-carbon alcohols to aromatics with zeolites has also attracted much attention in recent years [28,29]. However, the catalysts used in these processes undergo quick deactivation as a result of coke deposition, and most of the feed materials are synthesized separately from syngas. Therefore, the direct synthesis of aromatics from syngas should simplify the process, thereby making it more worthwhile and economical.

The approach to producing aromatics from syngas was put forward by Chang et al., who employed a composite catalyst combining a CO reduction part with ZSM-5 zeolite for the first time in 1979 [30]. Subsequently, a series of reaction pathways using modified FT catalysts or multiple-step processes that introduce certain intermediates (olefins or alcohols) were widely developed [31,32]. Recently, the concept of the oxide-zeolite (abbreviated as OX-ZEO) process was proposed by
Jiao et al. [33] and is a promising method for the one-step production of aromatics from syngas. The strategy is consequently attracting widespread interest and is becoming one of the research hotspots.

To date, there are many studies on this topic, but few reviews have been published to discuss the various catalytic systems and compare their differences. In this review, we displayed the feasibility of direct syngas conversion to aromatics by thermodynamic analysis. The reaction process and corresponding performance over different catalytic systems, including one-stage and two-stage routes, are brought into focus to enable better comprehension of this reaction. We attempt to discuss the challenges and future prospects of the direct syngas conversion process, thus providing general guidelines about the construction of catalysts.

\section{Thermodynamics}

The production of aromatics from syngas involves many complex reactions, like methanol synthesis, methanol dehydration, dehydrogenation cyclization, aromatization, alkylation, and water gas shift reactions [34]. Hence, besides the target benzene and its alkyl substitutes, a broad range of hydrocarbons, including $\mathrm{CH}_{4}$, low-carbon olefins, paraffins, and alcohols, are formed as products in this system, together with $\mathrm{CO}_{2}$ and $\mathrm{H}_{2} \mathrm{O}$ [35]. To analyze the thermodynamics of this process, a series of simplified reactions related to the formation of alkanes, alkenes and aromatics from syngas are employed here, as shown below. Among various hydrocarbons, propylene, propane, $p$-xylene, and mesitylene are chosen as the representatives.

$$
\begin{aligned}
\mathrm{CO}+2 \mathrm{H}_{2} & \rightarrow \mathrm{CH}_{3} \mathrm{OH} \\
3 \mathrm{CO}+7 \mathrm{H}_{2} & \rightarrow \mathrm{C}_{3} \mathrm{H}_{8}+3 \mathrm{H}_{2} \mathrm{O} \\
3 \mathrm{CO}+6 \mathrm{H}_{2} & \rightarrow \mathrm{C}_{3} \mathrm{H}_{6}+3 \mathrm{H}_{2} \mathrm{O} \\
8 \mathrm{CO}+9 \mathrm{H}_{2} & \rightarrow \mathrm{C}_{8} \mathrm{H}_{10}+8 \mathrm{H}_{2} \mathrm{O} \\
9 \mathrm{CO}+15 \mathrm{H}_{2} & \rightarrow \mathrm{C}_{9} \mathrm{H}_{12}+9 \mathrm{H}_{2} \mathrm{O}
\end{aligned}
$$

Based on the thermodynamic analysis (Fig. 1), the formation of methanol is unfavorable at the reaction temperature range of 563-773 $\mathrm{K}$ as the Gibbs free energy value is positive. However,
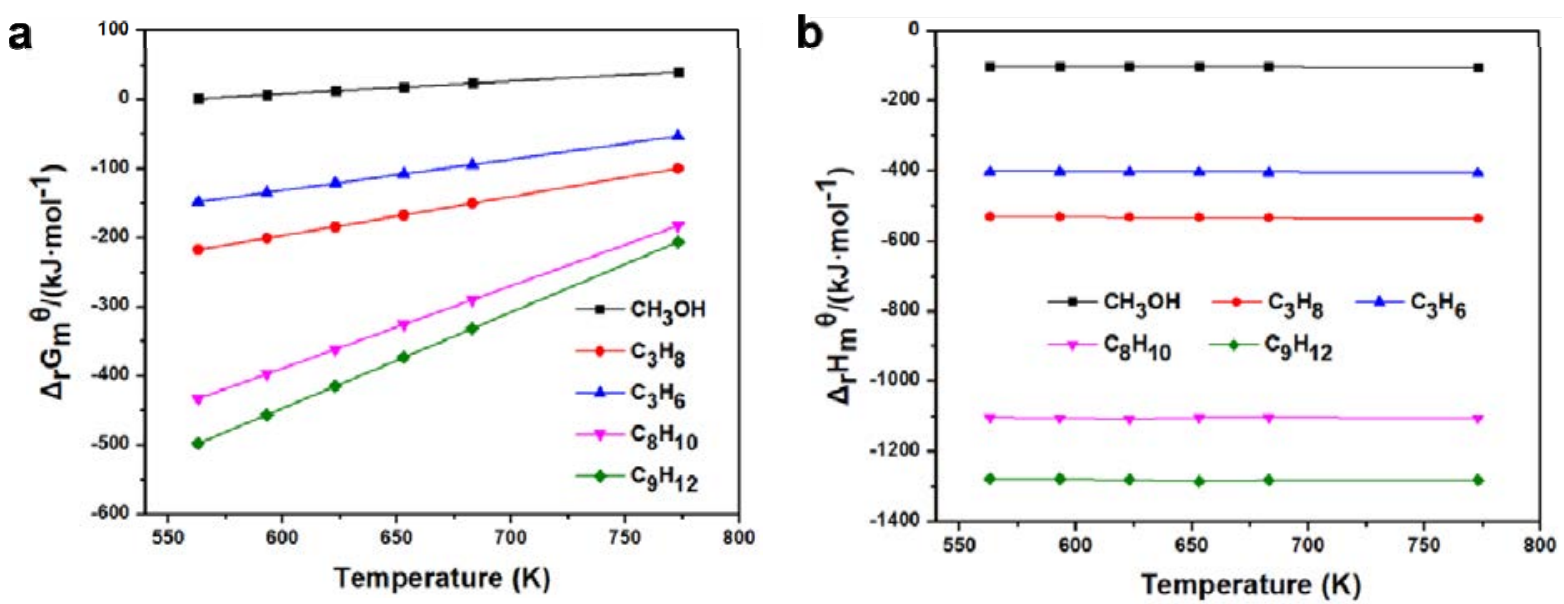

Fig. 1. Change in (a) Gibbs free energy and (b) reaction enthalpies with temperature of various reactions in the process of syngas conversion to aromatics. 
it is found that the Gibbs free energies of other reactions that also occur from syngas are less than zero under the same conditions, meaning that they are thermodynamically spontaneous. Furthermore, the relative energy values increase with an increase in the carbon number of the products, which indicates that high-carbon hydrocarbons are more thermodynamically favorable at high temperature. Additionally, the enthalpy values of all reactions are lower than zero in the entire reaction temperature range. The exothermic heat evolved during aromatics formation is especially larger than that evolved during the formation of other products, which corresponds to a distinct rise in temperature that is likely to influence the activity of catalysts [36].

\section{Catalyst design}

Generally, there are two approaches for producing aromatics from syngas. One is the direct transformation of syngas into aromatics over modified FT catalysts, and the other adopts the concept of composite catalysts that produce some intermediates first, which are then transformed into aromatics. The two kinds of catalysts and their corresponding reaction mechanisms are summarized and discussed below.

\subsection{Modified FT catalysts}

As the products obtained by conventional FT catalysts obey the Anderson Schulz Flory (ASF) distribution, the selectivity of aromatics is limited $[37,38]$. Dry et al. [39] reported that the percentage of aromatics among the products does not exceed $15 \%$ with traditional Fe- or Co-based catalysts at $2 \mathrm{MPa}$. Thus, modifications have been made by adding promoters or using acidic zeolites as supports for FT catalysts to improve the aromatic selectivity [40].

The addition of promoters to conventional FT catalysts might modulate the active sites and generate new functions, which is likely to enhance the aromatic yield [41]. By adding 2 wt $\% \mathrm{Pd}$ promoters into a $10 \mathrm{wt} \% \mathrm{Fe} / \mathrm{SiO}_{2}$ catalyst, $\mathrm{Nimz}$ et al. [42] found that the aromatic selectivity increased dramatically to $30.5 \%$ at the expense of methane and ethylene. By probing the structural changes of the catalysts, it was found that the PdFe alloy emerged except for the metallic $\alpha$-iron and ionic $\mathrm{Fe}^{2+}$ species. They proposed a model of a bifunctional catalyst system, in which paraffins and olefins were formed on the $\mathrm{Fe}\left(\mathrm{Fe}_{x} \mathrm{C}\right)$ component first, and then aromatics were generated by dehydrogenation and dehydrocyclization over the PdFe alloy, because Pd is an efficient reforming catalyst for converting paraffins into aromatics [42].

Typically, zeolites with a suitable pore structure and acidity are employed as supports for FT catalysts to combine the functions of shape-selectivity and aromatization, especially the ZSM-5 zeolite, which is the most suitable alternative as its pore geometry closely matches the size of aromatic hydrocarbons [43]. For example, $\mathrm{Xu}$ et al. [44] prepared a bifunctional Fe/HZSM-5 catalyst for the conversion of syngas. They found a synergistic effect of the active iron sites and HZSM-5, obtaining a CO conversion of about $90 \%$ and aromatic selectivity of about
$50 \%$ after more than $100 \mathrm{~h}$ under the conditions of $320^{\circ} \mathrm{C}, 2.0$ $\mathrm{MPa}$, and $4000 \mathrm{~h}^{-1}$, as shown in Fig. 2. A Co/HZSM-5 bifunctional catalyst was also adopted by Calleja et al. [45] for the direct synthesis of aromatics from syngas. The results revealed that the interaction between Co species and the zeolite surface significantly contributed to the activity. Moreover, the function of promoters in these bifunctional catalysts was studied by many researchers to maximize the synergistic behavior between metal parts and zeolite parts. Yan and co-workers [46] have synthesized aromatic-rich gasoline-range hydrocarbons from bio-syngas over a Pd-promoted Fe/HZSM-5 catalyst. It was detected that, instead of olefins, certain alcohols were formed as the reaction intermediates after the addition of Pd promoters, which promoted the catalytic activity and formation of aromatic hydrocarbons (shown in Scheme 1). Notably, the zeolite acidity plays a vital role in the product distribution. Besides the original $\mathrm{Si} / \mathrm{Al}$ ratio, the acid types (Brönsted and Lewis acid sites) and zeolite strength are also altered after loading different amounts of active metal species or promoters, which further influence the cracking probability and dehydrogenation ability of the catalysts. The addition of thoria into Co/HZSM-5 was well investigated by Calleja et al. [45], showing that the aromatic proportion in the liquid hydrocarbon fraction decreased because the zeolite acidity was affected by the promoter with a basic character.

Apart from ZSM-5-supported conventional Fe- and Co- catalysts, other kinds of FT catalysts were also applied in the formation of aromatics from syngas [47]. Liu et al. [48] used Mo/ZSM-5 as the catalyst and biomass-derived syngas with a low $\mathrm{H}_{2} / \mathrm{CO}$ molar ratio $\left(\mathrm{H}_{2} / \mathrm{CO}=1.0\right)$ as the feed gas, obtaining liquid hydrocarbons mainly composed of alkyl-substituted
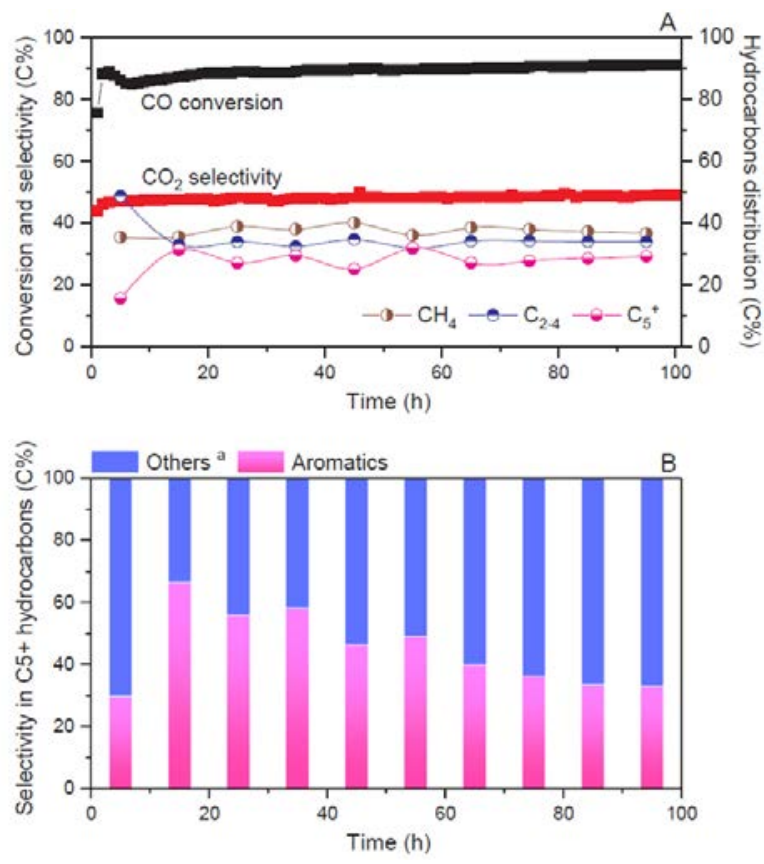

Fig. 2. Stability of the Fe/HZSM-5 catalyst. (A) Conversion and hydrocarbon distribution; (B) Selectivity in $\mathrm{C}_{5+}$ hydrocarbons. Reaction conditions: $320{ }^{\circ} \mathrm{C}, 2.0 \mathrm{MPa}, 4000 \mathrm{~h}^{-1}, 15 \% \mathrm{Fe} / \mathrm{HZ27}$. a $\mathrm{C}_{5+}$ hydrocarbons except for aromatics. Reproduced from reference [45] with permission from Elsevier. 


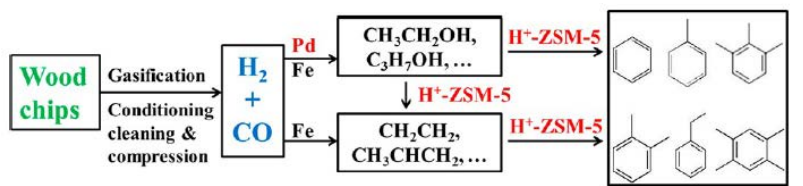

Scheme 1. Aromatic-rich gasoline-range hydrocarbons synthesized over the Pd-promoted Fe/H-ZSM-5 from woody biomass-derived syngas. Reproduced from reference [46] with permission from the American Chemical Society.

aromatics and lower branched and cyclized alkanes. During this catalytic process, alcohols were identified as the intermediates that formed on molybdenum metal sites and were subsequently converted into hydrocarbons on the acidic sites of zeolites. Other zeolites, like $\mathrm{Y}$ and $\beta$, could be also adopted as supports for Mo-based catalysts in this reaction, as displayed in Fig. 3. Though multiple methods have been attempted to increase the aromatic product fraction obtained over modified FT catalysts, most of the results are still less than $50 \%$, which greatly limits the application of this kind of catalyst.

\subsection{Composite catalysts}

Composite catalysts are used to combine the processes of CO conversion into intermediates and their further conversion into aromatics [49]. Compared with FT catalysts, composite catalysts show an enormous advantage in aromatic selectivity because the ASF rule does not apply to these processes. Thus, composite catalysts are receiving a lot of attention [50]. CO could either be converted over oxides into C1 intermediates, mainly including methanol and dimethyl ether [51] (shown in Scheme 2), or into low-carbon hydrocarbons over FT catalysts [52] (shown in Scheme 3). Both kinds of intermediates could then serve as raw materials to produce aromatics over acidic zeolites. Additionally, CO could be also converted into aromat-
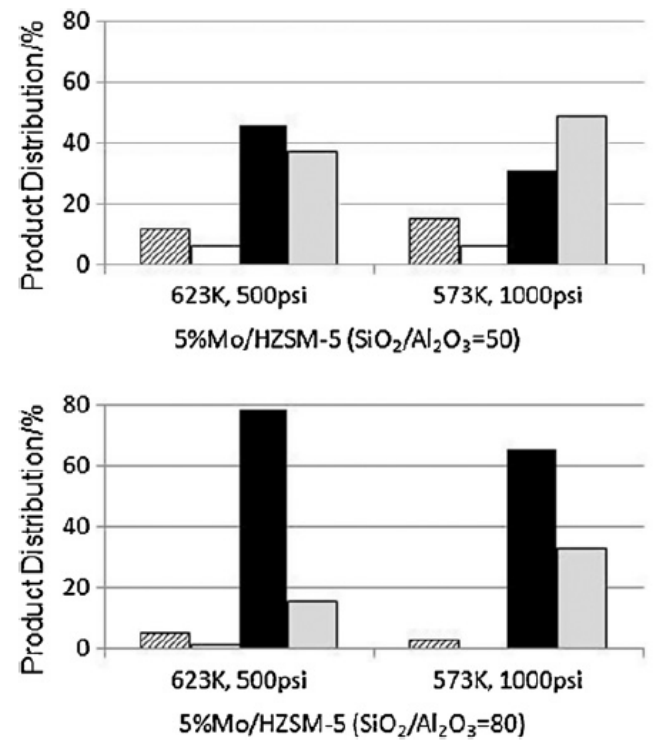

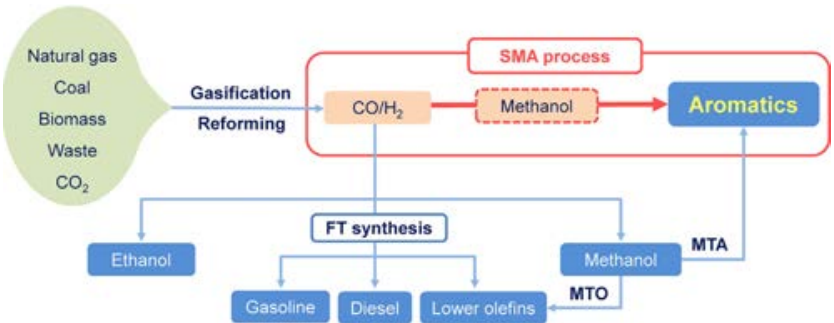

Scheme 2. Typical reaction processes related to syngas chemistry. The red-line route demonstrates the SMA process for the direct synthesis of aromatics via reaction coupling. Reproduced from reference [51] with permission from Elsevier.

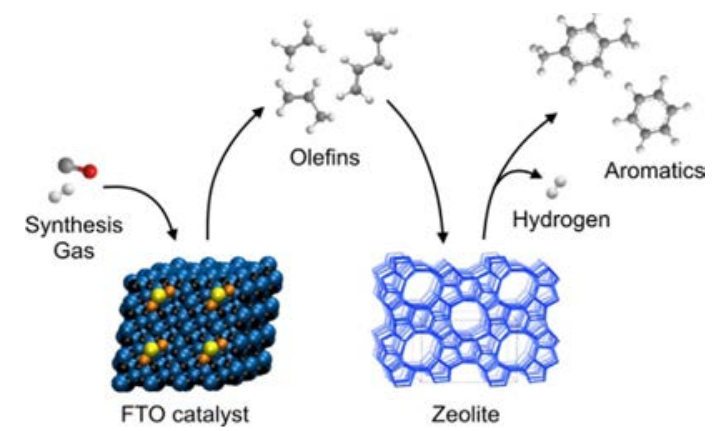

Scheme 3. Proposed reaction pathway for the conversion of synthesis gas to aromatics: conversion of synthesis gas to olefins on the FTO catalyst; dehydroaromatization of olefins to aromatics on the zeolite. Reproduced from reference [52] with permission from Wiley.

ics by coupling other processes. Given the different reaction routes, composite catalysts are divided into OX-ZEOs, FT catalysts-zeolites and other kinds for further discussion.

\subsubsection{Oxide-zeolite catalysts}

The physical mixture of effective oxides and zeolites for the direct transformation of $\mathrm{CO}$ into aromatics was proposed at a

Fig. 3. Product distributions in the oil phase from FT synthesis (FTS) over different catalysts. Reproduced from reference [48] with permission from Elsevier. 


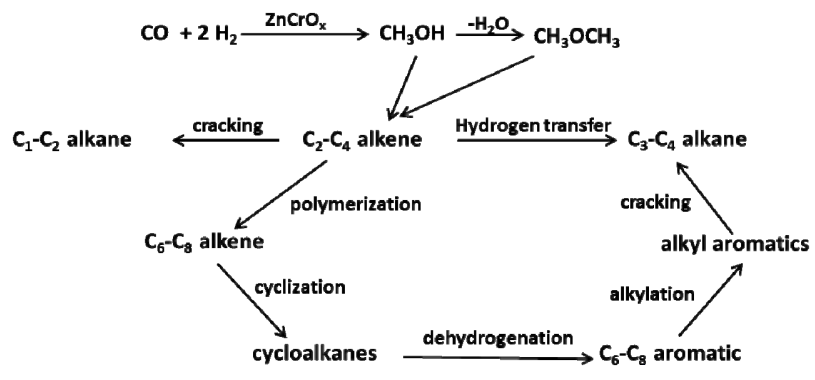

Fig. 4. Proposed reaction routes in the OX-ZEO process. Reproduced from reference [53] with permission from Royal Society of Chemistry.

very early stage by Chang et al. [30]. Lately, many researchers embarked on achieving better performance by deeply investigating the specific reaction mechanisms and the interaction of the bifunctionalities over composite catalysts. The generally accepted reaction pathways follow the steps shown in Fig. 4. CO is activated over the oxides and hydrogenated into methanol, which is transferred to the acidic sites of zeolites, where it forms light olefins by dehydration and $\mathrm{C}-\mathrm{C}$ coupling reactions. The olefins can be transformed into aromatics and long chain hydrocarbons by polymerization, cyclization, dehydrogenation, alkylation and hydrogen transfer reactions [53]. Besides the formation of a methanol intermediate, there are other reaction mechanisms based on composite catalyst systems. Chen et al. [54] used methanol and $\mathrm{CO}$ as the feed gas, a found a new aromatization mechanism involving the formation of methyl-2-cyclopenten-1-one (MCPO) intermediates that were further incorporated into aromatic rings. Yang et al. [55] reported that the ketene species is the surface intermediate that is generated on the partially reducible $\mathrm{ZnCrO}_{x}$. It can be further converted into aromatics over ZSM-5. The conclusion is confirmed by comparing the product distribution profile of this process with that of the process involving the conversion of methanol into aromatics. During the latter process, the in-situ transformation of the ketene intermediate greatly promotes the rightward shift of the equilibrium of CO hydrogenation, leading to a relatively high CO conversion. Additionally, $\mathrm{CO}$ is regarded to have a role in eliminating $\mathrm{H}$ species from the zeolite surface, thus facilitating the rate-determining dehydrogenative aromatization step and promoting aromatic selectivity [51]. This is quite consistent with the report of Li et al. [56], who studied the direct conversion of $\mathrm{CO}_{2}$ into aromatics by a tandem ZnZrO/ZSM-5 catalyst. They proposed that $\mathrm{H}$ species generated from olefin dehydrogenation over the zeolite could migrate to the oxide surface and participate in the $\mathrm{CO}_{2}$ hydrogenation reaction. This effect promoted the formation of aromatics with a selectivity of $73 \%$ at a $\mathrm{CO}_{2}$ conversion of $14 \%$. In addition, unlike the single methanol to hydrocarbons process, the presence of $\mathrm{H}_{2}$ as feed gas helps to suppress coke formation, thus contributing to the excellent stability of the OX-ZEO reaction system [51,57].

On the basis of reaction features, common methanol synthesis catalysts, such as $\mathrm{Zn}-\mathrm{Zr} / \mathrm{Cr}$ oxide, Cu-based oxide and Pd-based oxide catalyst, are employed in combination with ZSM-5 zeolite, which has the most suitable pore geometry for the formation of aromatics. Simard et al. [58] mixed ZSM-5 zeolite with $\mathrm{Zn}-\mathrm{Cr}$ oxide for the formation of aromatics from syngas. The detected products were mainly carbon dioxide, water and various hydrocarbons that were formed through the complete conversion of methanol. It was observed that the crystalline phases of oxides played different functions in the formation of intermediates. $\mathrm{Cr}_{2} \mathrm{O}_{3}$ mainly contributed to the synthesis of methanol, while $\mathrm{ZnCr}_{2} \mathrm{O}_{4}$ influenced the gas product distributions. A high yield of liquid hydrocarbons (up to $74 \%$ in total hydrocarbons) was obtained over the hybrid catalyst comprising the oxide with a low $\mathrm{Zn} / \mathrm{Cr}$ ratio. Cheng et al. [51] and his colleagues designed a $\mathrm{Zn}-\mathrm{ZrO}_{2} / \mathrm{H}-\mathrm{ZSM}-5$ bifunctional catalyst for the one-step conversion of syngas into aromatics. They successfully acquired aromatic products with $80 \%$ selectivity at $20 \%$ CO conversion and a remarkable stability over 1000 h, as shown in Fig. 5. Surprisingly, the undesired $\mathrm{CH}_{4}$ selectivity remained below $3 \%$ during this process. Dagle et al. [59] evaluated the performance of the composite $\mathrm{Pd} / \mathrm{ZnO} / \mathrm{Al}_{2} \mathrm{O}_{3}-\mathrm{HZSM}-5$ catalyst at $310^{\circ} \mathrm{C}, 300 \mathrm{psi}, 740 \mathrm{~h}^{-1}$ and $\mathrm{H}_{2} / \mathrm{CO}=2$. The liquid products are aromatic-rich and contain plenty of methylated benzene hydrocarbons. $\mathrm{Pd} / \mathrm{ZnO} / \mathrm{Al}_{2} \mathrm{O}_{3}$ and ZSM-5 showed excellent resistance to sintering and coke formation individually, and consequently demonstrated high stability for more than $50 \mathrm{~h}$. Cu-based catalysts are currently the commonly used industrial catalysts for methanol synthesis. Nevertheless, the temperature for methanol synthesis over $\mathrm{Cu}$-based catalysts is much lower (about $200^{\circ} \mathrm{C}$ ) than that for the aromatization reaction. Thus, modifications were made to decrease methane formation and increase methanol selectivity at high temperature. Co promoters were added to the $\mathrm{CuO}-\mathrm{Cr}_{2} \mathrm{O}_{3}$ oxide using a co-precipitation method by Mohanty et al. [60]. The oxide component was further mixed with MFI zeolite $(\mathrm{Si} / \mathrm{Al}=35)$ for the catalytic conversion of syngas. The results illustrated that the synergistic effect of Co promoters not only promoted CO conversion (increased from 28\% at 225 ${ }^{\circ} \mathrm{C}$ to $72 \%$ at $275{ }^{\circ} \mathrm{C}$ ), but also aided the formation of the $\mathrm{C}_{5+}$ fraction, with high yields of aromatic products.

Besides these well-known methanol synthesis catalysts, other reducible oxides were also used for the activation of CO. For example, the spinel-structured $\mathrm{ZnAlO}_{x}$ is also effective for the conversion of $\mathrm{CO}$ or $\mathrm{CO}_{2}$ into methanol, which could be further transformed into aromatics [61,62]. Moreover, the hydro-

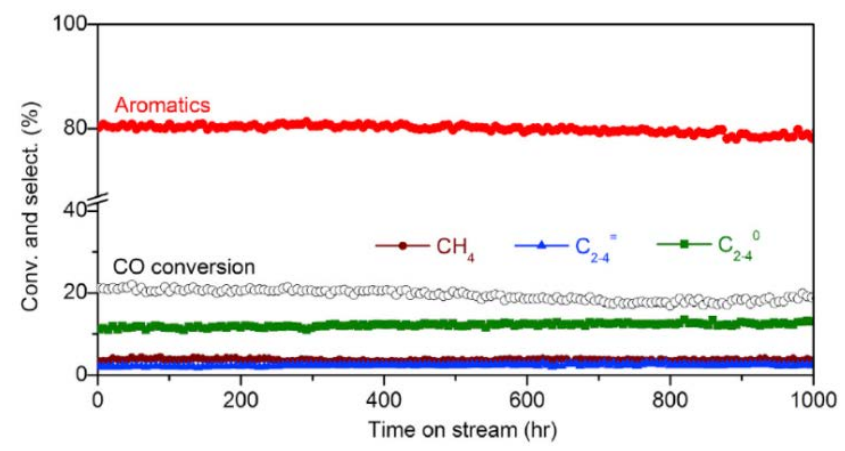

Fig. 5. Stability of the $\mathrm{Zn}-\mathrm{ZrO}_{2} / \mathrm{H}-\mathrm{ZSM}-5$ catalyst. Reaction conditions: catalyst weight $3.0 \mathrm{~g}$; $673 \mathrm{~K}$; $\mathrm{H}_{2} / \mathrm{CO}, 2: 1 ; 3 \mathrm{MPa} ; 25 \mathrm{~cm}^{3} \mathrm{~min}^{-1}$. Reproduced from reference [51] with permission from Elsevier. 
genation ability of mixed oxides is considered to play a pivotal role in both the selectivity and productivity of aromatics. Thus, the choice and modulation of oxides are also crucial [63]. Huang et al. [64] adopted a Ce-Zr oxide with tunable surface oxygen vacancies to couple with ZSM-5 zeolite for the direct conversion of syngas into aromatics. By adjusting the $\mathrm{Ce} / \mathrm{Zr}$ ratio and creating a good kinetic matching between $\mathrm{C}-0$ activation and C-C coupling, a high aromatic selectivity of $83.1 \%$ was achieved over the $\mathrm{Ce}_{0.2 \mathrm{Zr}} \mathrm{Zr}_{0} \mathrm{O}_{2} / \mathrm{ZSM}-5$ catalyst. Zhou et al. [65] used Mo-doped $\mathrm{ZrO}_{2}$ to modulate the hydrogenation ability and then combined it with H-ZSM-5 to obtain superior aromatic selectivity.

Taking the different functionalities of the two components in the composite catalysts into consideration, the oxides are mainly responsible for the activation of $\mathrm{CO}$ and the resulting activity, while zeolites are principally in charge of the product distribution. Yang et al. [66] presented a sheet-like ZSM-5 combined with $\mathrm{ZnCrO}_{\mathrm{x}}$, which increased aromatic selectivity because of the promoted diffusion of aromatics in zeolite crystals. Therefore, many studies are concentrating on the alteration of the pore size and acidity of zeolites $[67,68]$. Introducing promoters into zeolite is an effective way to change the character of zeolites. Zhang et al. [69] added different amounts of $\mathrm{MnCl}_{2}$ into HZSM- 5 and investigated the change of the product distribution over $\mathrm{Cu} / \mathrm{Zn} / \mathrm{Al}-\mathrm{HZSM}-5$ bifunctional catalyst, as displayed in Fig. 6. A high $p$-xylene selectivity and low 1,2,4,5-tetramethylbenzene selectivity was obtained after the addition of $2 \mathrm{wt} \% \mathrm{MnCl}_{2}$ into HZSM-5, because the adsorption and reaction of DME molecules on zeolites was affected by the change in the acidity and pore volume. Direct modification of the surface or channels of zeolites offers a method to modulate the pore size and local acidity. Zhang et al. [70] presented the use of a special core-shell Zn/Z5@S1 zeolite that acted as the zeolite part of the $\mathrm{Cr} / \mathrm{Zn}-\mathrm{Zn} / \mathrm{Z5} @ \mathrm{~S} 1$ hybrid catalyst to facilitate the oriented synthesis of para-xylene from syngas and reducing by-product formation. A considerable selectivity for $p a-$ ra-xylene $(27.6 \%$ in the total products and $77.3 \%$ in xylene) is exhibited at $55.0 \%$ CO conversion, which is shown in Fig. 7. Additionally, composite zeolites can provide new types of channels and moderate acid sites, which modulate the product distribution. For example, an HZSM-5/MnAPO-11 composite

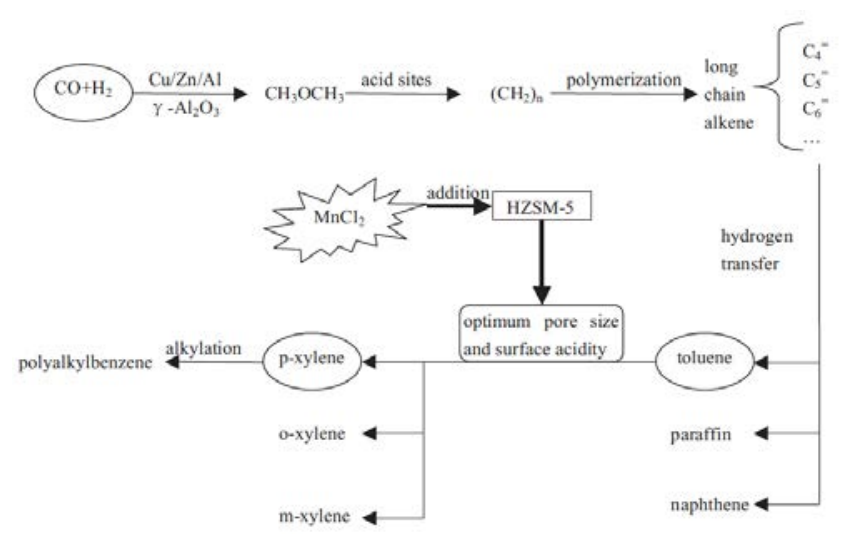

Fig. 6. Total reaction routes of syngas to aromatics via DME. Reproduced from reference [69] with permission from Elsevier.
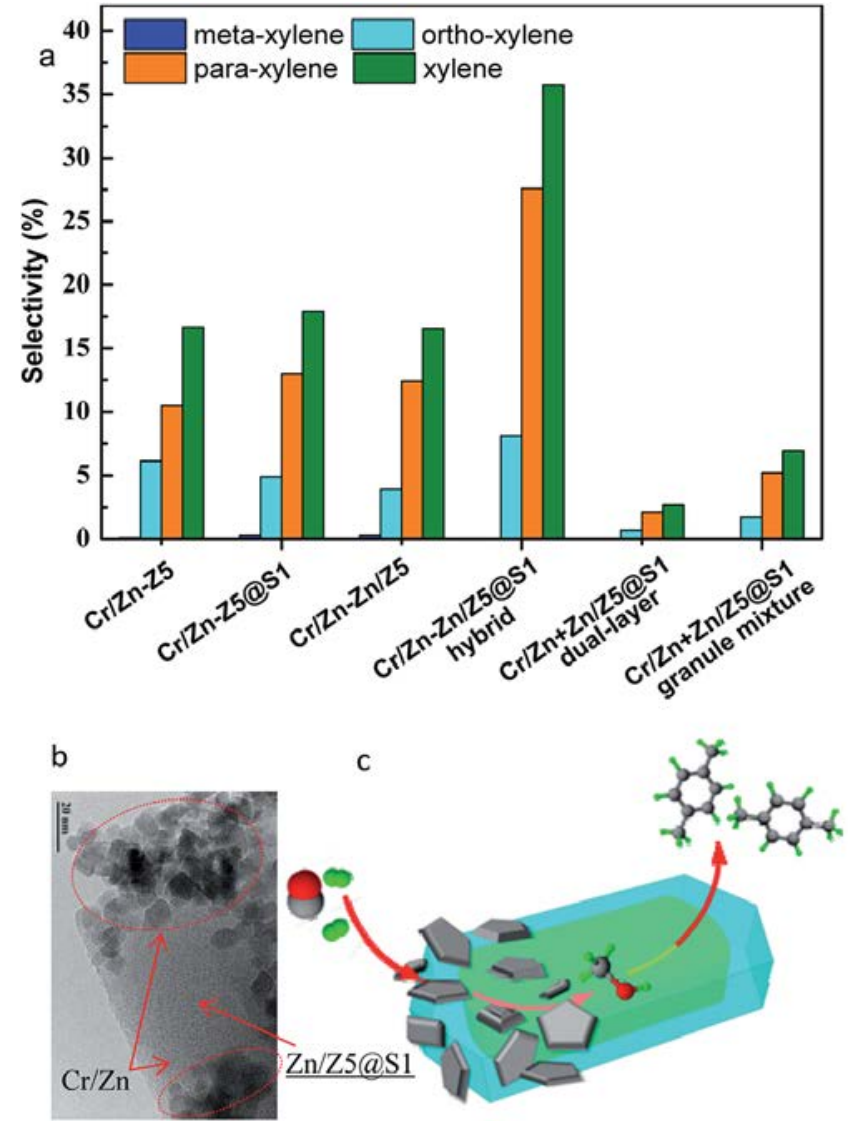

Fig. 7. (a) Distribution of total xylene and the isomers (OX, MX and PX) over various catalysts; (b) Transmission electron microscopy (TEM) image of the Cr/Zn-Zn/Z5@S1 hybrid catalyst; (c) Reaction mechanism of the one-pass selective syngas conversion to para-xylene over the hybrid catalyst Cr/Zn-Zn/Z5@S1. Reproduced from reference [70] with permission from Royal Society of Chemistry.

prepared via hydrothermal synthesis led to the production of high-octane gasoline from syngas in a two-stage reaction process [71].

As the optimum performance of the two active parts occurs under different environments, the reaction conditions and their mixing methods are crucial factors to ensure the good function of the active components. Arandes et al. [72] studied the use of $\mathrm{Cr}_{2} \mathrm{O}_{3}-\mathrm{ZnO} / \mathrm{ZSM}-5$ for the synthesis of gasoline at different conditions, finding that a maximum octane index of the product was obtained at $20 \mathrm{~atm}$ and $375^{\circ} \mathrm{C}$. The molecular weight of gasoline increased with the $\mathrm{Cr} / \mathrm{Zn}$ atomic ratio, pressure, $\mathrm{CO} / \mathrm{H}_{2}$ molar ratio, and space-time, and decreased with the $\mathrm{Si} / \mathrm{Al}$ ratio and temperature. Another factor that needs to be considered is the intimacy between oxide and zeolite in the composite catalyst, which has a significant impact on product selectivity [73-75]. Based on the alteration in mixing methods of the two catalyst components, a dramatic change in product distribution has been achieved. Yang et al. [76] studied in detail the influence of mixing methods and proposed an iterative reactions' mechanism, which indicated that the intermediates underwent a hydrogenation reaction on oxides, as revealed in Fig. 8. The reaction atmosphere and residence time of the intermediate on the internal particle inspired a different degree 


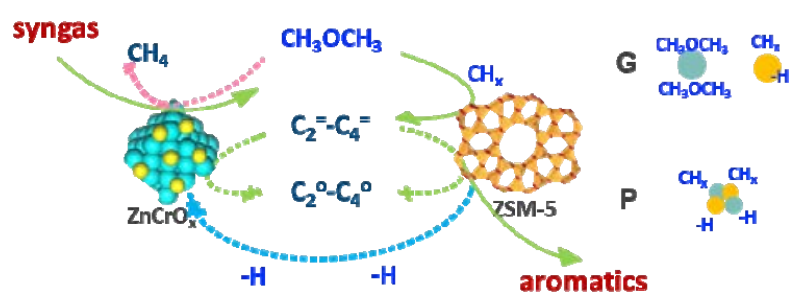

Fig. 8. Proposed reaction pathways and secondary reactions over composite catalysts. The dotted lines represent interactive reactions, G means granular mixing, and $\mathrm{P}$ means powder mixing. The reaction marked with a red line is more likely to occur on the oxide of a granular mixed catalyst. The blue line represents the transfer of $-H$ species from zeolite to oxide, which is prone to occur over the powder mixing catalyst. Reproduced from reference [76] with permission from Elsevier.

of iterative reactions. This alteration was caused by the corresponding changes in the particle interior and external diffusion with different intimacy, which led to a completely different hydrocarbon product selectivity.

\subsubsection{FT catalysts-zeolites catalysts}

Unlike oxide catalysts, CO can be converted into low-carbon hydrocarbons first on FT catalysts [77], followed by aromatization into aromatics, usually over a ZSM- 5 catalyst. The different reaction pathways with separate mechanisms lead to a diverse distribution of aromatics. Yang et al. [78] investigated the differences in product distribution at $330{ }^{\circ} \mathrm{C}, 4 \mathrm{MPa}$ and $\mathrm{H}_{2}: \mathrm{CO}=$ $2: 1$ by employing the composite catalysts $\mathrm{Fe}_{2} \mathrm{O}_{3}-\mathrm{SiO}_{2} / \mathrm{Nb}$-/Ni-modified HZSM-5 and $\mathrm{CuO}-\mathrm{ZnO}-\mathrm{Al}_{2} \mathrm{O}_{3} / \mathrm{Nb}-/ \mathrm{Ni}-$ modified HZSM-5 simultaneously (Fig. 9). It was observed that $\mathrm{Fe}_{2} \mathrm{O}_{3}-\mathrm{SiO}_{2}$-modified HZSM-5 had a higher BTX selectivity, while $\mathrm{CuO}-\mathrm{ZnO}-\mathrm{Al}_{2} \mathrm{O}_{3}$-modified HZSM-5 had a higher durene selectivity.

Currently, the main FT catalysts used for this tandem reaction are Fe-based catalysts, which can easily produce olefins. Moreover, promoters like $\mathrm{Na}, \mathrm{K}, \mathrm{Mn}, \mathrm{S}$ have frequently been added to further improve the activity and light olefin by changing the surface electronic state and basicity, as well as the carburization degree of the catalyst, leading to the enhancement of aromatic selectivity after combining with zeolites [79]. Weber et al. [52] established an intriguing process that can tailor the selectivity of aromatics and olefins by using a physical mixture of Na-S-Fe- $\mathrm{Al}_{2} \mathrm{O}_{3}$ and HZSM-5 zeolite. The carbon selectivity

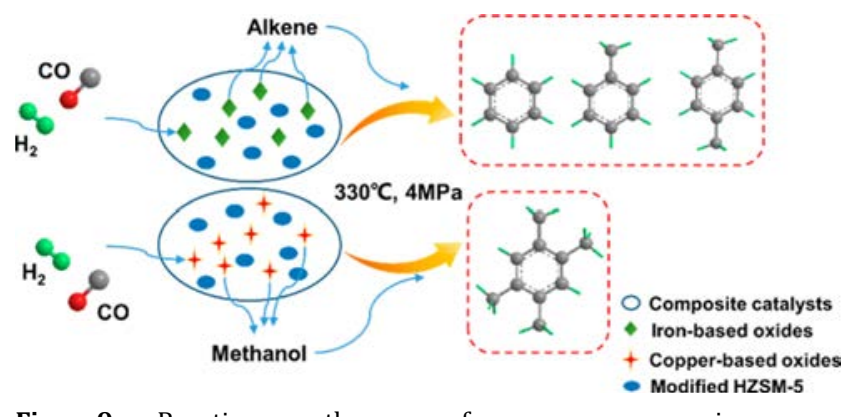

Fig. 9. Reaction pathways of syngas conversion over $\mathrm{Fe}_{2} \mathrm{O}_{3}-\mathrm{SiO}_{2}$-modified $\mathrm{HZ}$ and $\mathrm{CuO}-\mathrm{ZnO}-\mathrm{Al}_{2} \mathrm{O}_{3}$-modified $\mathrm{HZ}$ catalysts. Reproduced from reference [78] with permission from the American Chemical Society. toward the two products reached $73 \%$ (55\% C of lower olefins and $18 \% \mathrm{C}$ of aromatics). It is worth noting that the aromatization of olefins did not follow the hydrogen transfer pathway during this process. Cheng et al. [80] used a K-modified FeMnO/MoNi-ZSM-5 catalyst in a one-step conversion of syngas to aromatics and obtained a BTX selectivity of $56.4 \%$ at $4 \mathrm{MPa}$, $370{ }^{\circ} \mathrm{C}, 1395 \mathrm{~h}^{-1}$ and a volume flow ratio of $\mathrm{H}_{2} / \mathrm{CO}=2$. The addition of $\mathrm{K}$ could promote the $\mathrm{CO}$ adsorption and carburization of iron oxide, consequently increasing the catalyst stability and inhibiting the formation of $\mathrm{CH}_{4}$ and $\mathrm{CO}_{2}$. A similar result of approximately $98.1 \%$ CO conversion and $53.1 \%$ aromatic selectivity at $\mathrm{H}_{2} / \mathrm{CO}=2,1600 \mathrm{~h}^{-1}, 1.1 \mathrm{MPa}$ and $543 \mathrm{~K}$ was also obtained by Wang et al. [81], who adopted the tandem catalyst of $\mathrm{Fe} / \mathrm{MnO}$ with $\mathrm{Zn}-\mathrm{ZSM}-5$.

Co-based FT catalysts that could generate olefinic and oxygenated products were also adopted in combination with pentasil zeolites for the direct conversion of syngas. By adding some promoters, like $\mathrm{Mn}$, into the Co oxide system, methane formation was greatly suppressed but olefin formation was enhanced, favoring the formation of aromatic hydrocarbons eventually [82].

Similar to the OX-ZEO process, when combined with FT catalysts, zeolites also interfere with the aromatic selectivity. Research on the relationship between the acidity or pore structure and aromatic selectivity, which can provide relevant information about modification, is quite necessary to achieve better performance. Through systematical studies of physical mixtures of iron-based FTS catalysts and ZSM-5 zeolites with varying $\mathrm{Si} / \mathrm{Al}$ ratios and desilication treatments, Plana-Pallejà and his colleagues [83] found that a higher zeolite acidity contributed to the cracking reaction and the formation of heavier aromatic products, while a lower zeolite acidity led to a product shift toward the gasoline-range (iso-paraffin and olefin) fraction. Additionally, the products were almost completely distributed in the paraffin range over $\mathrm{Na}^{+}$-type zeolites with no acidity, similar to the result obtained over the sole iron FTS catalyst. Thus, increasing the accessibility of the hierarchical structure of the composite catalyst while preserving the zeolite acidity is beneficial for the formation of aromatics and a higher amount of small paraffins $\left(<\mathrm{C}_{4+}\right)$. Zhao et al. [84] precisely tuned the hierarchical pore size and Brønsted acidity of HZSM- 5 by controlling the alkali treatment conditions and the ion exchange degree. When coupled with a functional $\mathrm{Na}-\mathrm{Zn}-\mathrm{Fe}_{5} \mathrm{C}_{2}$ component, a stable stage with an aromatic selectivity of $51 \%$ and a $\mathrm{CO}$ conversion higher than $85 \%$ was achieved. Among many factors, the density and strength of the Brønsted acid sites over ZSM-5 zeolite seemed to play a vital role in the aromatic yield, as revealed in Fig. 10. Zeolites not only have a direct influence on the products, but may also have an effect on the state of active metal parts of Fe-based catalysts. Weber et al. [52] analyzed the change of Fe species when they were coupled with ZSM-5, detecting that the presence of zeolite enhanced the reduction degree of $\mathrm{Fe}$ in a more pronounced way (Fig. 11). The introduced amount of zeolite in the composite catalyst is also crucial for aromatic formation, as reported by Xu et al. [85]. They observed that an excess amount of zeolite suppressed the formation of Fe carbides and thus CO disso- 


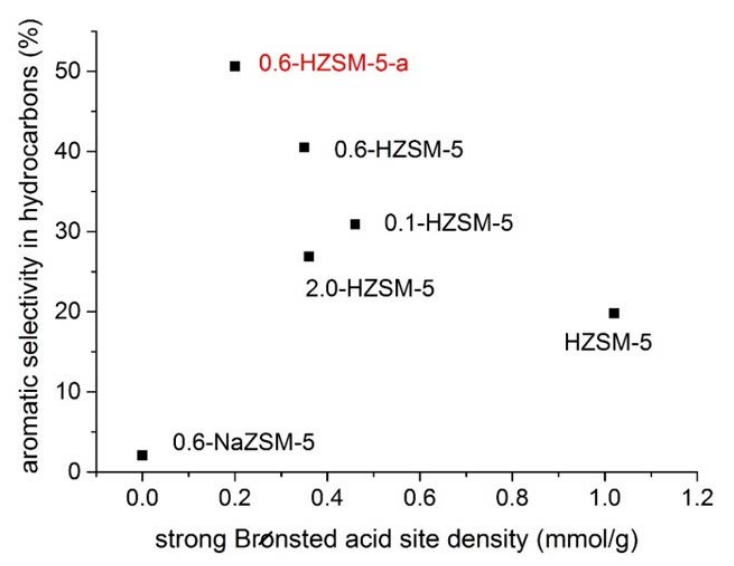

Fig. 10. Relationship between aromatic selectivity and the density of strong Brønsted acid sites in ZSM-5 zeolite. Reproduced from reference [84] with permission from Elsevier.
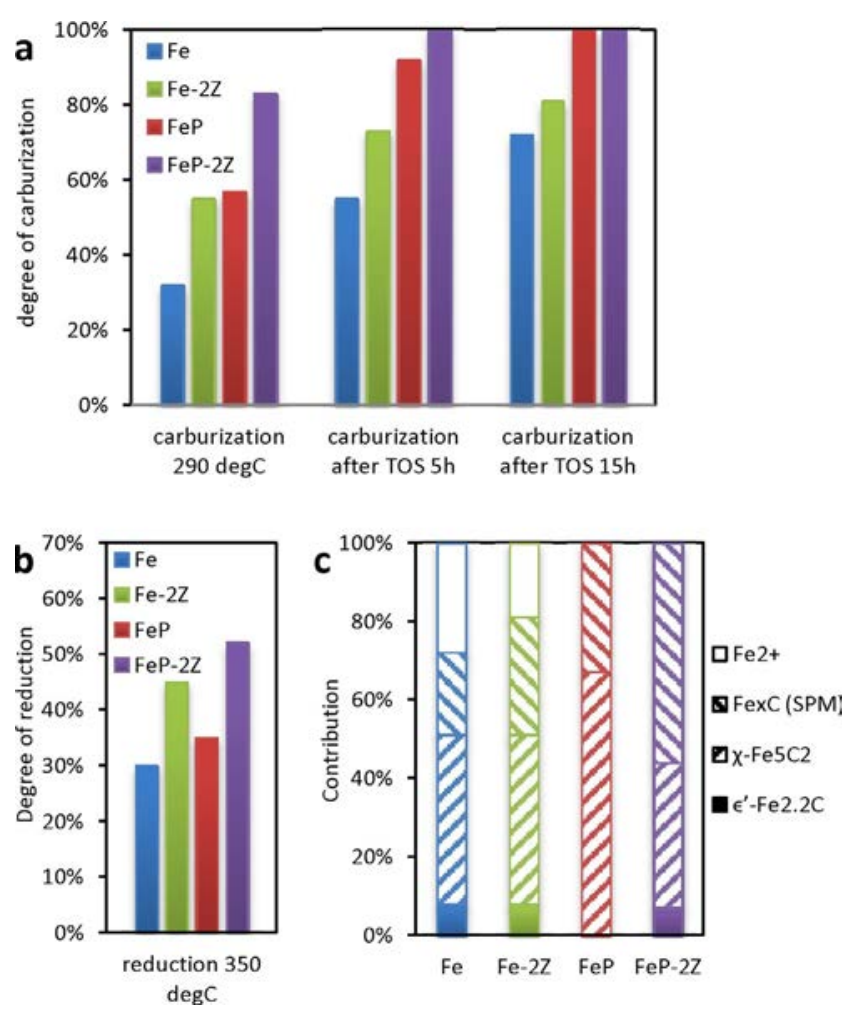

Fig. 11. Degree of reduction and carburization of mixed-bed experiments. (a) Degree of carburization of the two iron catalysts with and without zeolite as presented in a physical mixture after the in situ carburization step; (b) Degree of reduction of the two iron catalysts to $\mathrm{Fe}^{\circ}$ in the presence and absence of zeolite in a physical mixture after in situ reduction; (c) Fraction of $\mathrm{Fe}^{2+}$ oxide and iron carbides within the total iron atoms. Reproduced from reference [52] with permission from Wiley.

ciation, which led to lower CO conversion. Thus, an optimized match between the desired FT catalyst and a zeolite with suitable porosity and acidity is extremely essential for the harvesting of aromatics.

Moreover, the reaction conditions and mixing methods of the two active parts directly affect the aromatic selectivity. Xu et al. [86] reported that increasing reaction temperature facili-
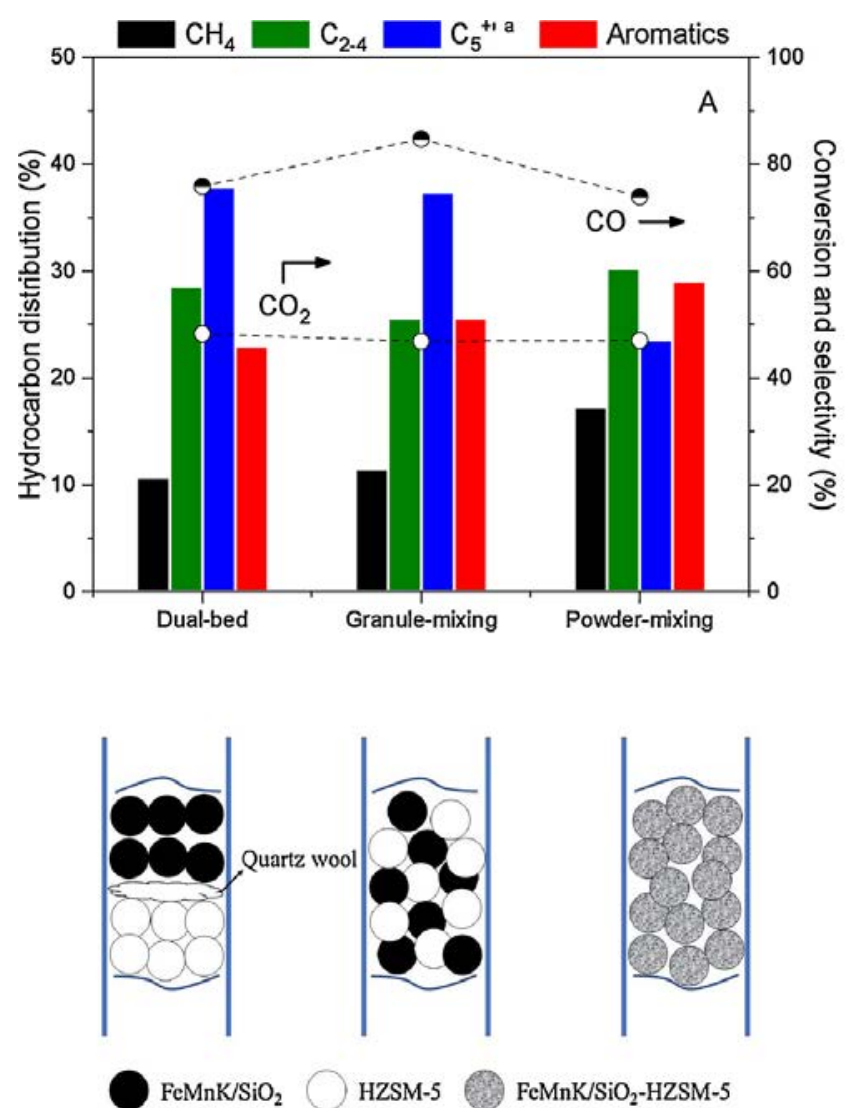

Fig. 12. Effect of the proximity of the two catalysts. (A) CO conversion and hydrocarbon distribution over different combinations of FeMnK/SiO 2 and HZSM-5 catalysts. TOS $=30 \mathrm{~h}$. Reproduced from reference [86] with permission from Elsevier.

tated the improvement of aromatic selectivity, while an increase in gas space velocity (GHSV) and pressure hindered the formation of aromatics. The product distribution is also obviously affected by the integration manner of the two active parts, as shown in Fig. 12. After the optimization of reaction conditions, an excellent aromatic selectivity of $57.17 \%$ was achieved with $83.8 \%$ CO conversion over a mixed-powder catalyst of $\mathrm{FeMnK} / \mathrm{SiO}_{2}$ and HZSM-5, which was much higher than the values achieved with other mixing methods. For the purpose of flexible control, dual-bed reactors that separately load FT catalyst and zeolite were designed as an alternative to physical mixing in a single catalytic reactor. Inui et al. [87] loaded the Fe-Mn-Ru catalyst, which exhibited high selectivity toward light alkenes with a significantly high syngas conversion in the first reactor. The formed light alkenes and $\mathrm{C}_{5+}$ aliphatic molecules were then transferred into the second reactor and converted into aromatics on $\mathrm{H}-\mathrm{Ga}$-silicate. Corsaro et al. [88] tested the dual-bed process of a Co-based catalyst and HZSM-5 zeolite, showing an impressive increase in the aromatic selectivity from zero to $28.4 \%$ compared to the single Co-based catalytic process, as well as a decrease in $\mathrm{CO}_{2}$ and $\mathrm{CH}_{4}$ selectivities (by $26.3 \%$ and $20.6 \%$, respectively). With further alterations to the reaction conditions of the ZSM-5 part, the LPG and aromatic selectivity displayed maximum values at $623 \mathrm{~K}$, HZSM-5 loading $=2.5 \mathrm{~g}$, and GHSV $=4.8 \mathrm{~L}_{\text {syngas }} \mathrm{g}_{\text {cat }}{ }^{-1} \mathrm{~h}^{-1}$. 


\subsection{Other hybrid catalyst systems}

As there are intermediates or by-products involved in the syngas conversion process, other kinds of hybrid catalyst systems were also examined to improve the yield of aromatics. For example, when a copper-based water gas shift catalyst was combined with Mo/Co/K/ZSM-5 or Mo/Ni/K/ZSM-5, CO conversion significantly increased from $25 \%$ to $90 \%$ with improved selectivity of heavy liquid hydrocarbons at $280{ }^{\circ} \mathrm{C}$ in a batch reactor. The liquid products were mainly alkyl-substituted benzene hydrocarbons, ranging from an average number of 1.3 to 4.5 methyl moieties per ring [89]. The hydrogenation of $\mathrm{CO}$ into aromatics was also observed to occur over hybrid catalysts in other catalytic processes, which may have a positive role in the catalytic performance. Ni et al. [62] used a composite catalyst of $\mathrm{ZnAlO}_{x}$ and H-ZSM-5 for the conversion of $\mathrm{CO}_{2}$ to aromatics. The generated $\mathrm{CO}$ from $\mathrm{CO}_{2}$ over $\mathrm{ZnAlO}_{\mathrm{x}}$ could be further converted by hydrogenation when using a high $\mathrm{H}_{2} / \mathrm{CO}_{2}$ ratio.

\section{Reactor design and reaction processes}

According to the reaction course demanded, the production of aromatics from syngas can be divided into two operations, i.e. single-reactor [59] and dual-reactor arrangements [90,91], as shown in Figs. 13-14. The single-reactor arrangement uses one reactor to get the final aromatic products from syngas with modified FT catalysts or composite catalysts. In a dual-reactor arrangement, two sequential reactors with methanol synthesis

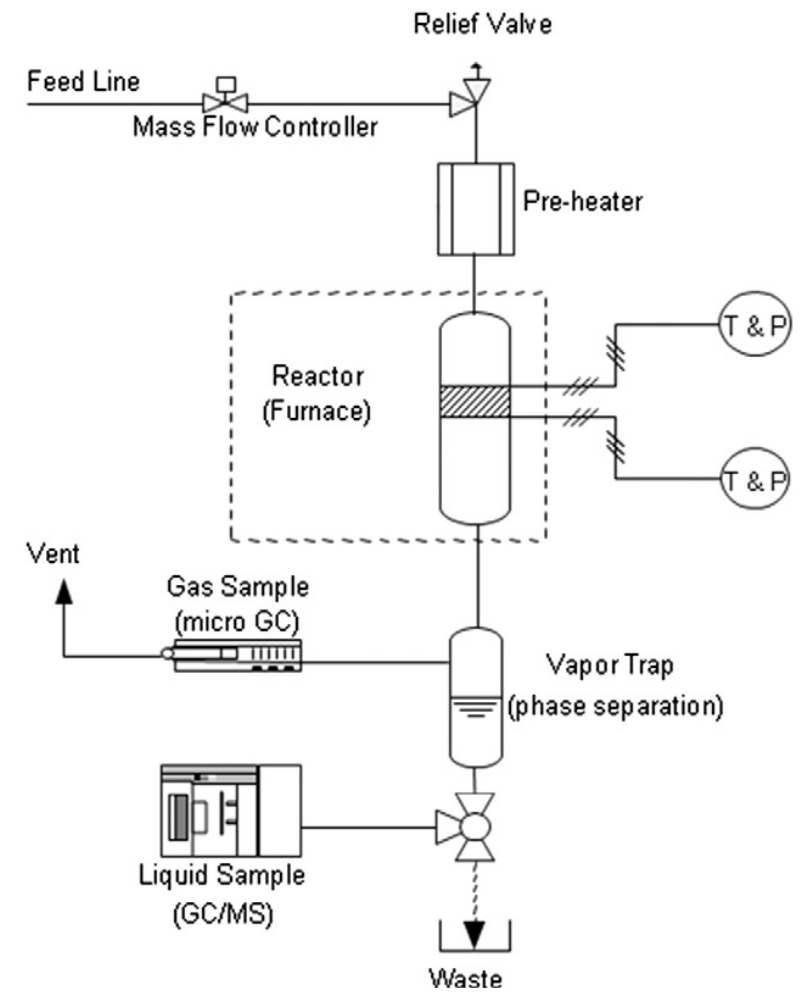

Fig. 13. Pressurized fixed bed flow reactor test stand. Reproduced from reference [59] with permission from Elsevier.

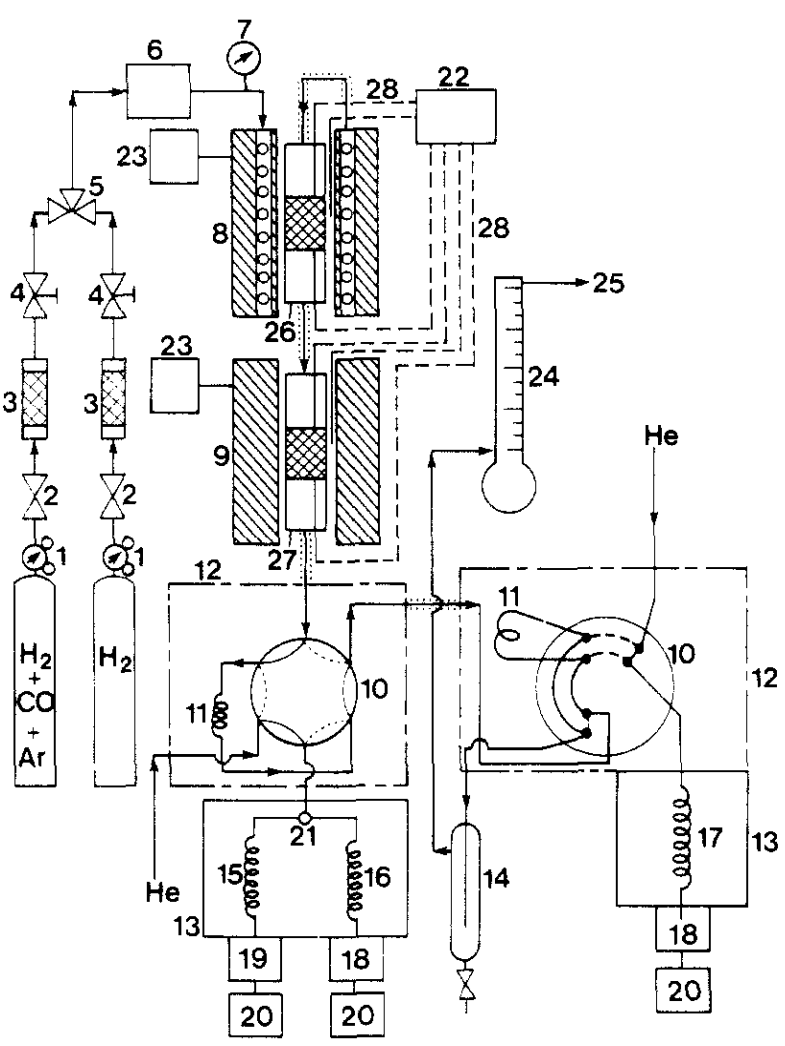

Fig. 14. Schematic diagram of dual-reactor and analytical system for on-line analysis. Reproduced from reference [90] with permission from the Royal Society of Chemistry.

catalysts or FT catalysts preserved in the first reactor and zeolites preserved in the second are connected to produce aromatics. Over the past decades, most studies still focused on the design of dual-reactor arrangements as it is facile to achieve optimal reaction conditions (temperature and pressure) for each kind of catalyst and thus obtain a high aromatic selectivity. Varma et al. [90] compared the performance of the same composite catalyst consisting of cobalt-nickel-zirconia catalyst and HZSM-5 zeolite which were filled in a single-reactor (follow bed and mixed bed) and a dual-reactor. It was found that the aromatic selectivity was nearly the same for all these operations at the same reaction temperature of $250{ }^{\circ} \mathrm{C}$. When the temperature of the second reactor was individually increased to $300{ }^{\circ} \mathrm{C}$ in the dual-reactor arrangement, the aromatic selectivity increased significantly from $25 \%$ to about $45 \%$. Moreover, zeolite catalysts can be regenerated separately and efficiently, which is beneficial for long-term operation [89]. However, the conversion of $\mathrm{CO}$ is still limited by the thermodynamic equilibrium of the methanol synthesis stage and the aromatic selectivity is limited by the ASF distribution over FT catalysts, so that the yield of aromatics cannot be high when adopting a dual-reactor arrangement [92]. The high cost of constructing two reactors and dealing with the various intermediates is another problem.

Nowadays, the single-reactor arrangement using composite catalysts is undergoing rapid development due to its simplicity and high efficiency $[93,94]$. In terms of the reaction performance, the in-situ tandem conversion of $\mathrm{C} 1$ intermediates from 
CO hydrogenation promotes a rightward shift in the reaction equilibrium, which results in a remarkable activity [95]. The aromatic selectivity can also be enhanced for the synergistic effect between oxides and zeolites, thereby breaking down the "seesaw" effect of activity and selectivity. Due to the in-situ water gas shift reaction, $\mathrm{CO}_{2}$ is produced along with $\mathrm{H}_{2}$ instead of wastewater. This advantage makes it possible to directly utilize coal- or biomass-derived syngas with a low $\mathrm{H}_{2} / \mathrm{CO}$ ratio $(<2)$ as the feedstock [96]. From the economic perspective, this arrangement is advantageous owing to the investment savings related to the formation and separation of intermediates when compared to the conventional dual-reactor arrangement. The operating cost and energy consumption are thus greatly cut down [97]. Nonetheless, the rapid deactivation of composite catalysts by coking or sintering and the difficulty in regeneration are likely to restrict the development of this process.

Except for these two operations, the co-production of aromatics from syngas seems to be a more competitive and economic alternative route, in which aromatics are produced together with other kinds of high-value hydrocarbon products. Guo et al. [98] used the dual-reactor arrangement with a copper-based catalyst and HZSM-5 zeolite respectively to produce gasoline and mesitylene simultaneously. The selectivity of isomeric alkanes and aromatics reached $85 \%$, and mesitylene occupied $20 \%-22 \%$ among the $\mathrm{C}_{5+}$ hydrocarbons. After the separation of mesitylene, gasoline products with a high-octane number could be obtained directly. This process does not only allow the maximum utilization of feedstock, but also brings certain economic benefits, and therefore has the most promising industrial prospects.

\section{Conclusions and future research directions}

Direct synthesis of aromatics from syngas is an effective way to alleviate the severe dependence on petroleum resources and make full use of renewable or fossil carbon-containing feedstock, such as biomass, coal or natural gas, thereby satisfying the demands of society, the market and strategic development. In the past decades, much attention has been paid to the reaction mechanisms, catalyst design and reaction process optimization to transform this technical approach into an industrially acceptable process. In this work, the feasibility of this process is further verified by analyzing the thermodynamics. The reaction processes, conditions and mechanisms over different catalysts are discussed in detail. To sum up, the reaction processes are categorized as single-reactor and dual-reactor arrangements, based on the operation methods.

In the single-reactor arrangement, the catalyst loading can be divided into two kinds: the modified FT catalysts, and composite catalysts, which are prepared by physical mixing or segmental packing. For modified FT catalysts, the aromatic selectivity is greatly limited because it tends to produce chain hydrocarbons instead of ring hydrocarbons. Additionally, the stability is poor owing to the easy formation of massive coke, which makes it unsuitable for wide application. Composite catalysts can be classified as OX-ZEOs and FT catalyst-zeolites according to the different reaction pathways on the two cata- lyst components. With the OX-ZEO catalysts, alcohols, mainly methanol, act as the intermediate that is formed by CO activation over oxides and further converted into aromatics by $\mathrm{C}-\mathrm{C}$ coupling over zeolites. This tandem reaction does not only enable a higher CO conversion due to the rightward shift in the CO hydrogenation reaction equilibrium, but also gives higher aromatic selectivity and better stability. Additionally, the formation of small amounts of $\mathrm{CH}_{4}$ and $\mathrm{H}_{2} \mathrm{O}$ in this process has the advantage of energy conservation and high economic efficiency. However, as the CO hydrogenation reaction is limited to the thermodynamic equilibrium, the conversion is low over composite catalysts. When it comes to the FT catalyst-zeolites, olefins or other low-carbon hydrocarbons are generated firstly on the FT catalysts, followed by aromatization over the zeolites. This process can provide a high CO conversion but poor aromatic selectivity, because the working temperatures of the two active parts are unmatched. FT catalysts need a relatively low temperature (around 473-623 K) to acquire high activity and good selectivity to olefins, or there would be a large quantity of $\mathrm{CH}_{4}$ formation and carbon deposition at high temperature. On the contrary, high aromatic activity over zeolites can only be achieved at high temperature (about $773 \mathrm{~K}$ ). For these two kinds of catalysts, a common problem is that the catalyst life and regeneration cycle are quite different. Compared with zeolites, the oxides and FT catalysts are more likely to deactivate and hard to be regenerated. Therefore, the primary task for getting better performance in these processes is to explore optimum matching conditions for both active parts. However, the relationship between the two active parts is still unclear, making it difficult to find good matching conditions. Figuring out how the active parts interact is of critical importance in the future. By solving these problems, the efficiency of the direct conversion of syngas into aromatics could be greatly improved, which has a long-term economic significance.

The advantages of dual-reactor arrangements for aromatic synthesis lie in the performance of individual processes at their optimal reaction conditions, thus avoiding the problem of mismatching and enhancing the aromatic selectivity. However, the synergistic effect which favors the promotion of CO conversion does not apply to this method.

Apart from increasing the possibility of industrial application, flexibly controlling the formation of a particular product with high selectivity is another future direction. By using some zeolites with special structures or modifying zeolites, the intermediates or products would be selectively produced, as reported by Jiao et al. [99] and Flores et al. [100]. Consequently, looking for deep insights into the fundamental reaction mechanism and the relationship between zeolite acidity and product selectivity is quite significant for the further development of research and industry. Given the recent advances in this research field, the direct synthesis of aromatics from syngas would certainly be a competitive route in the future.

\section{Acknowledgments}

The authors gratefully acknowledge the National Key R\&D Program of China (2016YFA0202804), the Strategic Priority 


\section{Graphical Abstract}

Chin. J. Catal., 2020, 41: 561-573 doi: S1872-2067(19)63346-2

\section{Direct conversion of syngas to aromatics: A review of recent studies}

Xiaoli Yang, Xiong Su, De Chen, Tao Zhang, Yanqiang Huang*

Dalian Institute of Chemical Physics, Chinese Academy of Sciences, China; University of Chinese Academy of Sciences, China;

Norwegian University of Science and Technology, Norway

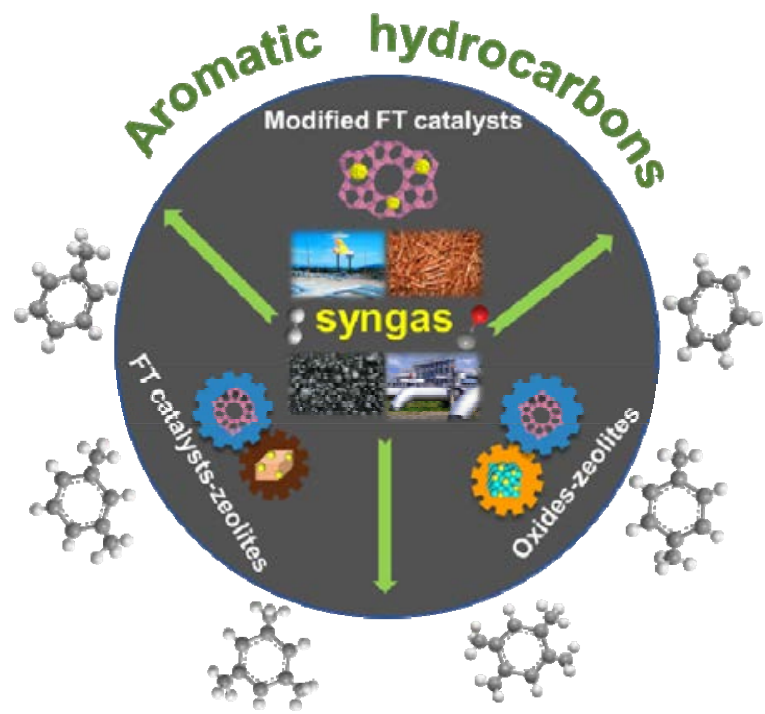

The conversion of syngas to aromatics provides an effective way to make full use of the renewable or fossil carbon-containing feedstocks, satisfying the demand of society, the market and strategic development.

Research Program of the Chinese Academy of Sciences (XDB17020400), the National Natural Science Foundation of China (21506204, 21476226), Dalian Science Foundation for Distinguished Young Scholars (2016RJ04), and the Youth Innovation Promotion Association CAS for financial support.

\section{References}

[1] P. Courty, J. F. Gruson, Oil Gas Sci. Technol, 2001, 56, 515-524.

[2] A. Demirbas, Energy Sources, Part A, 2007, 29, 677-684.

[3] C. C. Yu, S. K. Shen, Pet. Sci., 2008, 5, 67-72.

[4] P. Gao, S. G. Li, X. N. Bu, S. S. Dang, Z. Y. Liu, H. Wang, L. S. Zhong, M. H. Qiu, C. G. Yang, J. Cai, W. Wei, Y. H. Sun, Nat. Chem., 2017, 9, 1019-1024.

[5] S. Asthana, C. Samanta, A. Bhaumik, B. Banerjee, R. K. Voolapalli, B. Saha, J. Catal., 2016, 334, 89-101.

[6] C. Baltes, S. Vukojevic, F. Schuth, J. Catal., 2008, 258, 334-344.

[7] X. Q. Wu, S. T. Xu, W. N. Zhang, J. D. Huang, J. Z. Li, B. W. Yu, Y. X. Wei, Z. M. Liu, Angew. Chem. Int. Ed., 2017, 56, 9039-9043.

[8] G. Leendert Bezemer, J. H. Bitter, H. P. C. E. Kuipers, H. Oosterbeek, J. E. Holewijn, X. D. Xu, F. Kapteijn, A. Jos van Dillen, K. P. de Jong, J. Am. Chem. Soc., 2006, 128, 3956-3964.

[9] J. C. Kang, S. L. Zhang, Q. H. Zhang, Y. Wang, Angew. Chem. Int. Ed., 2009, 48, 2565-2568.

[10] K. Cheng, J. C. Kang, S. W. Huang, Z. Y. You, Q. H. Zhang, J. S. Ding, W.
Q. Hua, Y. C. Lou, W. P. Deng, Y. Wang, ACS Catal., 2012, 2, 441-449.

[11] K. Cheng, B. Gu, X. L. Liu, J. C. Kang, Q. H. Zhang, Y. Wang, Angew. Chem. Int. Ed., 2016, 55, 4725-4728.

[12] Y. Q. Song, X. X. Zhu, S. J. Xie, Q. X. Wang, L. Y. Xu, Catal. Lett., 2004, $97,31-36$

[13] X. X. Guan, N. Li, G. J. Wu, J. X. Chen, F. X. Zhang, N. J. Guan, J. Mol. Catal. A, 2006, 248, 220-225.

[14] M. Fischer, X. Jiang, Fuel, 2016, 183, 386-395.

[15] N. Viswanadham, A. R. Pradhan, N. Ray, S. C. Vishnoi, U. Shanker, T. S. R. Prasada Rao, Appl. Catal. A, 1996, 137, 225-233.

[16] P. C. Lai, C. Y. Hsieh, C. H. Chen, Y. C. Lin, Catalysts, 2017, 7, 259.

[17] S. Kim, G. Park, S. K. Kim, Y. T. Kim, K. W. Jun, G. Kwak, Appl. Catal. B, 2018, 220, 191-201.

[18] Y. K. Zhang, Y. X. Qu, D. L. Wang, X. C. Zeng, J. D. Wang, Ind. Eng. Chem. Res., 2017, 56, 12508-12519.

[19] F. Denardin, O. W. Perez-Lopez, Fuel, 2019, 236, 1293-1300.

[20] X. G. Guo, G. Z. Fang, G. Li, H. Ma, H. J. Fan, L. Yu, C. Ma, X. Wu, D. H. Deng, M. M. Wei, D. L. Tan, R. Si, S. Zhang, J. Q. Li, L. T. Sun, Z. C. Tang, X. L. Pan, X. H. Bao, Science, 2014, 344, 616-619.

[21] L. Wang, L. Tao, M. Xie, G. Xu, J. Huang, Y. Xu, Catal. Lett., 1993, 21, 35-41.

[22] D. Wang, J. H. Lunsford, M. P. Rosynek, J. Catal., 1997, 169, 347-358.

[23] S. Ma, X. Guo, L. Zhao, S. Scott, X. Bao, J. Energy Chem., 2013, 22, $1-20$. 
[24] T. Yashima, S. Ejiri, K. Kato, M. M. Ishaq, M. Tanigawa, T. Komatsu, S. Namba, Stud. Surf. Sci. Catal., 1996, 100, 447-454.

[25] T. Komatsu, M. Mesuda, T. Yashima, Appl. Catal. A, 2000, 194-195, 333-339.

[26] J. Zhang, W. Qian, C. Kong, F. Wei, ACS Catal., 2015, 5, 2982-2988.

[27] D. Freeman, R. P. K. Wells, G. J. Hutchings, J. Catal., 2002, 205, 358-365.

[28] A. Kecskeméti, R. Barthos, F. Solymosi, J. Catal., 2008, 258, 111-120.

[29] J. W. Jun, Z. Hasan, C. U. Kim, S. Y. Jeong, S. H. Jhung, J. Nanosci. Nanotechnol., 2016, 16, 4377-4385.

[30] C. D. Chang, W. H. Lang, A. J. Silvestri, J. Catal., 1979, 56, 268-273.

[31] S. Sartipi, M. Makkee, F. Kapteijn, J. Gascon, Catal. Sci. Technol., 2014, 4, 893-907.

[32] M. J. Valero-Romero, S. Sartipi, X. Sun, J. Rodriguez-Mirasol, T. Cordero, F. Kapteijn, J. Gascon, Catal. Sci. Technol., 2016, 6, 2633-2646.

[33] F. Jiao, J. J. Li, X. L. Pan, J. P. Xiao, H. B. Li, H. Ma, M. M. Wei, Y. Pan, Z. Y. Zhou, M. R. Li, S. Miao, J. Li, Y. F. Zhu, D. Xiao, T. He, J. H. Yang, F. Qi, Q. Fu, X. H. Bao, Science, 2016, 351, 1065-1068.

[34] K. Fujimoto, Y. Kudo, H. Tominaga, J. Catal., 1984, 87, 136-143.

[35] N. Guan, Y. Liu, M. Zhang, Catal. Today, 1996, 30, 207-213.

[36] L. Jiao, [MS Dissertation], East China University of Science and Technology, Shanghai, 2017.

[37] A. Y. Khodakov, W. Chu, P. Fongarland, Chem. Rev., 2007, 107, 1692-1744.

[38] B. Chen, D. Wang, X. Duan, W. Liu, Y. Li, G. Qian, W. Yuan, A. Holmen, X. Zhou, D. Chen, ACS Catal., 2018, 8, 2709-2714.

[39] M. E. Dry, J. Chem. Technol. Biotechnol., 2002, 77, 43-50.

[40] B. Chen, X. Zhang, W. Chen, D. Wang, N. Song, G. Qian, X. Duan, J. Yang, D. Chen, W. Yuan, Ind. Eng. Chem. Res., 2018, 57, 11554-11560.

[41] A. Alayat, E. Echeverria, D. N. Mcllroy, A. G. McDonald, Fuel Process. Technol., 2018, 177, 89-100.

[42] M. Nimz, G. Lietz, J. Völter, K. Lazar, L. Guczi, Catal. Lett., 1988, 1, 93-98.

[43] C. Wang, X. Y. Sun, J. Xu, G. D. Qi, W. Y. Wang, X. L. Zhao, W. Z. Li, Q. Wang, F. Deng, J. Catal., 2017, 354, 138-151.

[44] Y. Xu, J. Liu, G. Ma, J. Wang, J. Lin, H. Wang, C. Zhang, M. Ding, Fuel, 2018, 228, 1-9.

[45] G. Calleja, A. De Lucas, R. Van Grieken, Appl. Catal., 1991, 68, 11-29.

[46] Q. Yan, Y. Lu, C. Wan, J. Han, J. Rodriguez, J. Yin, F. Yu, Energy Fuels, 2014, 28, 2027-2034.

[47] Y. W. Lu, J. Hu, J. Han, F. Yu, J. Energy Inst., 2016, 89, 782-792.

[48] S. Liu, A. C. Gujar, P. Thomas, H. Toghiani, M. G. White, Appl. Catal. A, 2009, 357, 18-25.

[49] Y. Wang, J. Energy Chem., 2016, 25, 169-170.

[50] J. Su, D. Wang, Y. Wang, H. Zhou, C. Liu, S. Liu, C. Wang, W. Yang, Z. Xie, M. He, ChemCatChem, 2018, 10, 1536-1541.

[51] K. Cheng, W. Zhou, J. Kang, S. He, S. Shi, Q. Zhang, Y. Pan, W. Wen, Y. Wang, Chem, 2017, 3, 334-347.

[52] J. L. Weber, I. Dugulan, P. E. de Jongh, K. P. de Jong, ChemCatChem, 2018, 10, 1107-1112.

[53] X. Yang, X. Su, B. Liang, Y. Zhang, H. Duan, J. Ma, Y. Huang, T. Zhang, Catal. Sci. Technol., 2018, 8, 4338-4348.

[54] Z. Chen, Y. Ni, Y. Zhi, F. Wen, Z. Zhou, Y. Wei, W. Zhu, Z. Liu, Angew. Chem., 2018, 130, 12729-12733.

[55] J. Yang, X. Pan, F. Jiao, J. Li, X. Bao, Chem. Commun., 2017, 53, 11146-11149.

[56] Z. Li, Y. Qu, J. Wang, H. Liu, M. Li, S. Miao, C. Li, Joule, 2018, 3, $124-135$.
[57] S. S. Arora, D. L. S. N. Ieskens, A. Malek, A. Bhan, Nat. Catal., 2018, 1, 666-672.

[58] F. Simard, U. A. Sedran, J. Sepulveda, N. S. Figoli, H. I. de Lasa, Appl. Catal. A, 1995, 125, 81-98.

[59] R. A. Dagle, J. A. Lizarazo-Adarme, V. L. Dagle, M. J. Gray, J. F. White, D. L. King, D. R. Palo, Fuel Process. Technol., 2014, 123, 65-74.

[60] P. Mohanty, K. K. Pant, J. Parikh, D. K. Sharma, Fuel Process. Technol., 2011, 92, 600-608.

[61] Y. Ni, Z. Chen, Y. Fu, Y. Liu, W. Zhu, Z. Liu, Nat. Commun., 2018, 9, 3457.

[62] Y. Ni, Y. Liu, Z. Chen, M. Yang, H. Liu, Y. He, Y. Fu, W. Zhu, Z. Liu, ACS Catal., 2019, 9, 1026-1032.

[63] N. Li, F. Jiao, X. Pan, Y. Ding, J. Feng, X. Bao, ACS Catal., 2019, 9, 960-966.

[64] Z. Huang, S. Wang, F. Qin, L. Huang, Y. Yue, W. Hua, M. Qiao, H. He, W. Shen, H. Xu, ChemCatChem, 2018, 10, 4519-4524.

[65] W. Zhou, S. Shi, Y. Wang, L. Zhang, Y. Wang, G. Zhang, X. Min, K. Cheng, Q. Zhang, J. Kang, ChemCatChem, 2011, 3, 334-347.

[66] J. Yang, K. Gong, D. Miao, F. Jiao, X. Pan, X. Meng, F. Xiao, X. Bao, J. Energy Chem., 2019, 35, 44-48.

[67] B. Li, B. Sun, X. Qian, W. Li, Z. Wu, Z. Sun, M. Qiao, M. Duke, D. Zhao, J. Am. Chem. Soc., 2013, 135, 1181-1184.

[68] K. Van der Borght, R. Batchu, V. V. Galvita, K. Alexopoulos, M. F. Reyniers, J. W. Thybaut, G. B. Marin, Angew. Chem. Int. Ed., 2016, 55, 12817-12821.

[69] Q. Zhang, Y. Tan, C. Yang, H. Xie, Y. Han, J. Ind. Eng. Chem., 2013, 19, 975-980.

[70] P. Zhang, L. Tan, G. Yang, N. Tsubaki, Chem. Sci., 2017, 8, 7941-7946.

[71] J. Li, Y. Tan, Q. Zhang, Y. Han, Fuel, 2010, 89, 3510-3516.

[72] J. M. Arandes, J. Erena, A. G. Gayubo, J. Bilbao, H. I. De Lasa, Chem. Eng. Commun., 1999, 174, 1-19.

[73] Z. Li, J. Wang, Y. Qu, H. Liu, C. Tang, S. Miao, Z. Feng, H. An, C. Li, ACS Catal., 2017, 7, 8544-8548.

[74] X. Liu, W. Zhou, Y. Yang, K. Cheng, J. Kang, L. Zhang, G. Zhang, X. Min, Q. Zhang, Y. Wang, Chem. Sci., 2018, 9, 4708-4718.

[75] D. L. S. Nieskens, A. Ciftci, P. E. Groenendijk, M. F. Wielemaker, A. Malek, Ind. Eng. Chem. Res., 2017, 56, 2722-2732.

[76] X. Yang, T. Sun, J. Ma, X. Su, R. Wang, Y. Zhang, H. Duan, Y. Huang, T. Zhang, J. Energy Chem., 2019, 35, 60-65.

[77] D. Wang, B. Chen, X. Duan, D. Chen, X. Zhou, J. Energy Chem., 2016, 25, 911-916.

[78] T. Yang, L. Cheng, N. Li, D. Liu, Ind. Eng. Chem. Res., 2017, 56, 11763-11772.

[79] Z. Yang, X. Pan, J. Wang, X. Bao, Catal. Today, 2012, 186, 121-127.

[80] L. Cheng, C. Meng, T. Yang, N. Li, D. Liu, Energy Fuels, 2018, 32, 9756-9762.

[81] D. Wang, H. Zeng, N. Guan, Chin. J. Catal., 2002, 23, 333-335.

[82] G. Bäurle, K. Guse, M. Lohrengel, H. Papp, Stud. Surf. Sci. Catal., 1993, 75, 2789-2792.

[83] J. Plana-Pallejà, S. Abelló, C. Berrueco, D. Montané, Appl. Catal. A, 2016, 515, 126-135.

[84] B. Zhao, P. Zhai, P. Wang, J. Li, T. Li, M. Peng, M. Zhao, G. Hu, Y. Yang, Y. W. Li, Q. Zhang, W. Fan, D. Ma, Chem, 2017, 3, 323-333.

[85] Y. Xu, D. Liu, X. Liu, Appl. Catal. A, 2018, 552, 168-183.

[86] Y. Xu, J. Liu, G. Ma, J. Wang, Q. Wang, J. Lin, H. Wang, C. Zhang, M. Ding, Mol. Catal., 2018, 454, 104-113.

[87] T. Inui, T. Kuroda, T. Takeguchi, A. Miyamoto, Appl. Catal., 1990, 61, 219-233.

[88] A. Corsaro, T. Wiltowski, D. Juchelková, S. Honus, Pet. Sci. Technol., 2014, 32, 2497-2505. 
[89] R. Wijayapala, F. Yu, C. U. Pittman Jr, T. E. Mlsna, Appl. Catal. A, 2014, 480, 93-99.

[90] R. L. Varma, N. N. Bakhshi, J. F. Mathews, S. H. Ng, Ind. Eng. Chem. Res., 1987, 26, 183-188.

[91] J. Zhang, X. Sun, J. Qiao, T. Tuo, G. Fu, X. Min, Clean Coal Technol, 2013, 19, 60-62.

[92] X. Q. Shen, J. C. Kang, W. Niu, M. H. Wang, Q. H. Zhang, Y. Wang, Catal. Sci. Technol., 2017, 7, 3598-3612.

[93] P. Zhu, J. Sun, G. Yang, G. Liu, P. Zhang, Y. Yoneyama, N. Tsubaki, Catal. Sci. Technol., 2017, 7, 2695-2699.

[94] H. Zhou, S. Liu, J. Su, C. Liu, L. Zhang, W. Jiao, Y. Wang, Ind. Eng.
Chem. Res., 2018, 57, 6815-6820.

[95] R. Brosius, M. Claeys, Chem, 2017, 3, 202-204.

[96] Y. Chen, Y. Xu, D. Cheng, Y. Chen, F. Chen, X. Lu, Y. Huang, S. Ni, J. Appl. Chem. Biotechnol, 2015, 90, 415-422.

[97] K. Xiao, Z. Bao, X. Qi, X. Wang, L. Zhong, K. Fang, M. Liu, Y. Sun, Chin. J. Catal., 2013, 34, 116-129.

[98] Z. Guo, M. Kang, Y. Tan, Z. Ren, D. Lu, C. Fu, J. Fuel Chem. Technol., 1991, 19, 320-326.

[99] F. Jiao, X. Pan, K. Gong, Y. Chen, G. Li, X. Bao, Angew. Chem. Int. Ed., 2018, 57, 4692-4696.

[100] J. H. Flores, M. I. P. da Silva, Catal. Lett., 2016, 146, 1505-1516.

\title{
合成气直接转化制取芳烃研究进展
}

\author{
杨晓丽, $\mathrm{a}, \mathrm{c}$, , 苏 雄 ${ }^{\mathrm{a}}$, 陈 德 ${ }^{\mathrm{c}}$, 张 涛, , 黄延强, ${ }^{\mathrm{a},}$ \\ a 中国科学院大连化学物理研究所, 辽宁大连116023, 中国

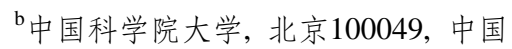 \\ “挪威科技大学化学工程系, 特隆赫姆7494, 挪威
}

\begin{abstract}
摘要: 芳烃类化合物是石化行业重要的基础原料. 非石油基碳资源经合成气直接转化制取芳烃具有重要的应用前景, 但该 过程仍存在着芳烃收率低以及催化剂稳定性差等难题. 近年来相关工作取得重要进展, 研究人员尝试通过高效催化剂的 设计和操作条件的优化以获得更好的催化反应性能. 本综述首先对该过程进行了热力学分析, 并根据催化剂体系对相关 研究成果进行分类总结, 主要包括改性FT催化剂和复合催化剂. 然后, 对各类催化剂体系的反应性能特点和机理进行了深 入探讨.

改性FT催化剂常采用添加助剂或引入分子篮载体的方法调变反应中间体在传统FT催化剂上的反应路径, 以促进芳烃 的生成. 但是, 该过程倾向于生成链烃而致使芳烃选择性受到限制, 而且容易形成积炭, 催化剂稳定性差. 复合催化剂可分 为氧化物-分子篮和FT-分子篮催化剂, 合成气首先在氧化物或者FT催化剂上生成某些亚稳态中间物种, 随后扩散至分子篮 孔道内经芳构化转化为芳烃. 对于氧化物-分子篮复合催化剂, $\mathrm{CO}$ 在氧化物上活化并生成醇类(主要是甲醇), 随后在分子篮 上进行C-C偶联、环化、芳构, 生成芳烃. 在该串联反应中, 由于中间产物的不断转化, 不仅使CO加氢反应的平衡右移, 提 升转化率, 而且增加了芳烃的收率与反应的稳定性. 另外, 该过程 $\mathrm{CH}_{4}$ 产物的选择性极低. 对于FT-分子篮复合催化剂, 合成 气首先在高温FT催化剂上生成低碳烃类, 然后转移至分子篎孔道内进行芳构化, 该方法可以获得较高的 CO转化率但芳烃 选择性仍比较低.

文章还详细描述了针对不同过程的反应器设计, 包括单反应器和双反应器. 在单反应器中可装填改性FT催化剂或物 理混合的复合催化剂. 对于复合催化剂, 存在两种活性组分的优化反应条件不一致以及混合方式影响反应活性和产物分 布等问题. 因此, 探索更佳的反应工艺条件对于实现合成气直接转化制芳烃的工业应用具有重要意义. 双反应器则是将复 合催化剂的两种功能组分分开装填, 使分步过程分别在各自最佳反应条件下进行, 从而避免了不匹配的问题. 最后, 该综 述展望了合成气直接转化制芳烃过程存在的挑战和应用前景, 为更好地设计催化剂、构建反应路径和优化工艺条件提供指 导.
\end{abstract}

关键词: 合成气; 芳烃; 改性FT催化剂; 复合型催化剂; 反应器

收稿日期: 2019-09-17. 接受日期: 2019-10-17. 出版日期: 2020-04-05.

*通讯联系人. 电话: (0411) 84685940; 电子信箱: yqhuang@dicp.ac.cn

基金来源：国家重点研发计划(2016YFA0202804); 中国科学院战略性先导科技专项(XDB17020400); 国家自然科学基金 (21506204, 21476226); 大连市杰出青年科学基金(2016RJ04); 中国科学院青年创新促进会.

本文的电子版全文由Elsevier出版社在ScienceDirect上出版(http://www.sciencedirect.com/science/journal/18722067). 